\title{
Microstructural and wear characterizations of Ultra-Dispersed Diamond (UDD) reinforced Cu-15 wt.\% Ti composites fabricated via mechanical alloying and sintering
}

\author{
H. Kaftelen ${ }^{1 *}$, M. L. Öveçoğlu \\ ${ }^{1}$ Karadeniz Technical University, Department of Metallurgical and Materials Engineering, Trabzon 61080, Turkey \\ ${ }^{2}$ Istanbul Technical University, Department of Metallurgical and Materials Engineering, Maslak 34469, Istanbul, Turkey
}

Received 8 February 2016, received in revised form 12 June 2016, accepted 13 June 2016

\begin{abstract}
In this study, effects of ultra-dispersed nanodiamond content on the microstructure and wear properties of $\mathrm{Cu}-15$ wt.\% Ti matrix composite were investigated. Samples were prepared by mechanical alloying and sintering at $890^{\circ} \mathrm{C}$ for $2 \mathrm{~h}$ under $\mathrm{H}_{2}$ gas atmosphere. Microstructural changes and dry sliding wear characterizations of sintered samples were investigated by a field emission scanning electron microscope (FESEM), and their phase characteristics were carried out using X-ray diffractometer (XRD). Electron microscopy investigations revealed that a good bonding between nanodiamond particles and $\mathrm{Cu}$ matrix could not be maintained due to the formation of free copper layers and the presence of high oxygen amount at the interface. The results taken from worn surfaces showed that high content of nanodiamond (10 wt.\%) with oxide particles led to low wear resistance due to poor bonding between $\mathrm{Cu}$ 15 wt.\% Ti matrix and nanodiamond particles which were pulled out during dry sliding wear.
\end{abstract}

K e y w or d s: ultra-dispersed nanodiamond powders, microstructure, wear resistance

\section{Introduction}

Copper has an excellent electrical conductivity at high temperatures (up to $800^{\circ} \mathrm{C}$ ) as well as excellent thermal conductivity and corrosion resistance. However, low abrasion and wear resistance of copper limit its use in many other applications [1]. These limitations are often circumvented by dispersing a stronger ceramic material in the copper matrix. In the literature, $\mathrm{Al}_{2} \mathrm{O}_{3}[2,3], \mathrm{NbC}[4], \mathrm{Fe}_{3} \mathrm{C}$ [5], $\mathrm{SiC}$ [6], diamond [7-9] have commonly been used as reinforcements for $\mathrm{Cu}$ matrix. Among these, nanodiamond particles are quite attractive due to their unique mechanical and tribological properties, including extreme hardness and inertness to chemical attack [10-12]. In recent years, several attempts have been made in utilizing nanodiamond particles as reinforcement in the $\mathrm{Al}[13,14], \mathrm{Ni}$, and Fe matrices [15] owing to their high surface energy which allows an effective structure interaction with utilized matrices. Advantages can be taken from extremely high surface areas, sur- face charges and self-lubrication [16, 17] properties of diamond nanoparticles and the ductility of the copper matrix, obtaining a composite with mechanically strong material. However, a homogeneous distribution and good interfacial bonding of the reinforcement with the matrix are required for improving the mechanical and wear properties of the composites. Many efforts have been made to investigate thermal and physical properties of diamond reinforced $\mathrm{Cu}$ composites fabricated by using different techniques such as casting [8] and powder metallurgy route involving the mixing and conventional sintering [7], pressureless sintering [18], ball milling and spark plasma sintering [19], hot pressing [20]. Thanks to bonding between diamond particles and $\mathrm{Cu}$ matrices, some active elements such as $\mathrm{Ti}$, $\mathrm{B}$, Cr, and $\mathrm{Zr}$ have been added to improve the interface associated with precipitation of some intermetallic phases such as $\mathrm{Cu}_{3} \mathrm{Ti}, \mathrm{CuTi}, \mathrm{TiB}_{2}, \mathrm{TiC}$, etc. [8, 21-23]. It was reported $[8,9]$ that the strong bonding between diamond and copper was obtained with the addition of $\mathrm{Ti}$ and this led to heat and load transfer

*Corresponding author: tel.: +90 462 3774039; e-mail address: kaftelen@ktu.edu.tr 
increment. Titanium was used as an interfacial binder in a number of studies in order to improve the interfacial bonding strength between the copper matrix and $\mathrm{SiC}[24,25]$, diamond [26].

The amount of published literature on nanodiamond reinforced copper matrix alloys is rather limited and primarily concerned with electronic applications of these composites. There are also some reported investigations on the utilization of nanodiamond particles as reinforcement in $\mathrm{Cu}$ matrix composites [20, $27,28]$. In these investigations, the difficulties in obtaining well-structured composites arising from both homogeneous dispersion of nanodiamond and deficient bonding between diamond and copper were explained $[20,28]$. In all studies, $\mathrm{Cu}$ phase is not alloyed with a transition metal, and it is utilized as a pure matrix phase. Thus, there is still a lack of knowledge in the archival literature regarding $\mathrm{Cu}$-based alloys reinforced with nanodiamond particles. The present study aims to fulfil this gap. In the present investigation, $\mathrm{Cu}$ pre-alloyed with 15 wt.\% Ti was used as a matrix and different amounts of nanodiamond particles (1 and $10 \mathrm{wt.} \%$ ) were incorporated using high energy ball milling. Microstructural changes and wear characterizations of sintered composites were evaluated as a function of the nanodiamond content.

\section{Experimental procedure}

Elemental electrolytic copper $(\mathrm{Cu})$ (Alfa Aesar ${ }^{\mathrm{TM}}$, $99 \%$ purity, -325 mesh), titanium (Alfa Aesar ${ }^{\mathrm{TM}}$, 99.5\% purity, -325 mesh), and ultra-dispersed nanodiamond (UDD) (ALIT Co., up to $99.5 \%$ pure diamond, average size $50 \mathrm{~nm}$ ) powders were used in the present investigation. The detailed information about UDD powders was presented in our previous work [13]. In this study, in order to improve the bonding between $\mathrm{Cu}$ and UDD particles, $15 \mathrm{wt} . \% \mathrm{Ti}$ was added to the $\mathrm{Cu}$ matrix [26]. $\mathrm{Cu}$ and $\mathrm{Ti}$ powders were blended to constitute the composition $\mathrm{Cu}-15$ wt.\% $\mathrm{Ti}$ (hereafter referred to be as $\mathrm{Cu} 15 \mathrm{Ti}$ ). As-blended powders were mechanically alloyed (MA'd) for $120 \mathrm{~min}$ in a high energy ball mill (Spex ${ }^{\mathrm{TM}}$ 8000D, New Jersey, USA) with a speed of $1200 \mathrm{rpm}$ using a steel vial with steel balls having a diameter of $6.36 \mathrm{~mm}$. To prevent oxidation during MA process, the vials were sealed inside a Plaslabs ${ }^{\mathrm{TM}}$ glove box under purified Ar gas (99.995\% purity). The ball-to-powder weight ratio (BPR) was $7: 1$. 1 wt.\% stearic acid was used as a process control agent (PCA) to inhibit cold-welding and agglomeration during MA. The mean particle size of pre-alloyed Cu15Ti powders was $7.9 \pm 1.2 \mu \mathrm{m} .1$ and 10 wt.\% of ultra-dispersed nano-diamond (UDD) powders were added to Cu15Ti alloy powders. Powder blends having the compositions of $\mathrm{Cu}-15$ wt.\% Ti-1 wt.\% UDD and $\mathrm{Cu}-15$ wt.\% Ti-10 wt.\% UDD (hereafter referred

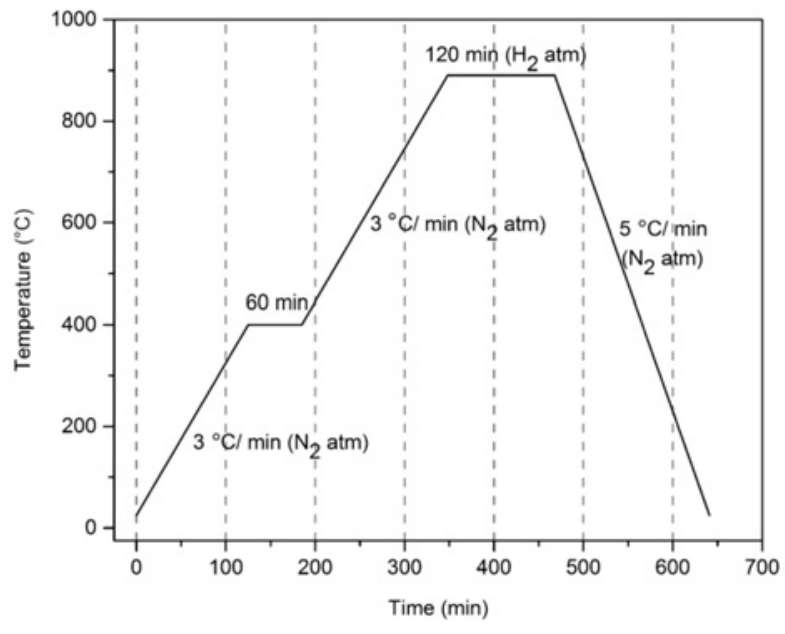

Fig. 1. Thermal profile used in the sintering of samples.

to as $\mathrm{Cu} 15 \mathrm{Ti} / 1 \mathrm{UDD}$ and $\mathrm{Cu} 15 \mathrm{Ti} / 10 \mathrm{UDD}$, respectively) were further MA'd for 120 min using the same conditions. In the present study, on the basis of MA runs for different durations, an optimum milling time of 120 min was chosen to achieve the milling efficiency and restrict the contamination from the milling media. Thermal investigations were carried out in a differential scanning calorimeter (DSC) $\left(\mathrm{TA}^{\mathrm{TM}}\right.$, New Castle, USA). Samples of $\sim 7 \mathrm{mg}$ contained in $\alpha$-alumina crucible were heated up to $900^{\circ} \mathrm{C}$ with a heating rate of $10^{\circ} \mathrm{C} \mathrm{min}{ }^{-1}$. During the heating process, a mixture of 96 vol. $\%$ Ar and 4 vol. $\% \mathrm{H}_{2}$ gases were introduced into the furnace at a flow rate of 30 and $5 \mathrm{ml} \mathrm{min}^{-1}$, respectively.

Mechanically alloyed powders were cold pressed uniaxially using a constant pressure of $200 \mathrm{MPa}$ in a steel mold to form a $12 \mathrm{~mm}$ cylindrical compact. The compacts were sintered at $890^{\circ} \mathrm{C}$ in a furnace (Unitherm $^{\mathrm{TM}} 1161 \mathrm{~V}$, Pittsburg, USA) for $2 \mathrm{~h}$. Figure 1 gives the detailed thermal profile and atmospheres used in the sintering process.

Microstructural and phase characteristics of sintered $\mathrm{Cu} 15 \mathrm{Ti} / 1 \mathrm{UDD}$ and $\mathrm{Cu} 15 \mathrm{Ti} / 10$ UDD composite samples were conducted by using X-ray Diffractometry (XRD) and Scanning Electron Microscopy (SEM) techniques. A Bruker ${ }^{\mathrm{TM}}$ D8 Advance XRD was used with a standard $\mathrm{Cu} \mathrm{K} \alpha$ radiation source employing a step size of $0.02^{\circ}$ in $2 \theta$. The sintered samples were ground manually using $\mathrm{SiC}$ papers. After grinding, the alloyed powders and sintered samples were polished using $0.3 \mu \mathrm{m} \mathrm{Al}_{2} \mathrm{O}_{3}$ powders on a soft cloth prior to XRD analyses. The sintered samples were mechanically broken into pieces in both longitudinal and transverse directions to allow for the investigation of the fracture surfaces. A Jeol ${ }^{\mathrm{TM}}$ JSM $7000 \mathrm{~F}$ field emission scanning electron microscope (FESEM) operating at a voltage of $15 \mathrm{kV}$ equipped with an IXRF $^{\mathrm{TM}}$ energy dispersive spectrometer (EDS) was used to assess sur- 
face morphology and fracture surface of the sintered composites as well as their qualitative chemistry. Prior to SEM investigations, polished samples were etched in a solution ammonium $\left(\mathrm{NH}_{4} \mathrm{OH}\right)(20 \mathrm{ml})$, hydrogen peroxide $\left(\mathrm{H}_{2} \mathrm{O}_{2}\right)(8 \mathrm{ml})$, and distilled water $(20 \mathrm{ml})$ [29]. Vickers microhardness tests on sintered samples were conducted using a Shimadzu ${ }^{\mathrm{TM}}$ microhardness tester under a load of $100 \mathrm{~g}$ for $10 \mathrm{~s}$. Sliding wear experiments were conducted on a Tribotech ${ }^{\mathrm{TM}}$ Oscillating Tribotester using $1.587 \mu \mathrm{m}$ steel balls (100 CR6-62 HRC) under an applied force of $2 \mathrm{~N}$. The tests were conducted at room temperature in a laboratory atmosphere with a sliding speed of $10 \mathrm{~mm} \mathrm{~s}^{-1}$, a stroke length of $5 \mathrm{~mm}$ and a sliding distance of $30 \mathrm{~m}$. Worn surfaces were examined using the $\mathrm{Jeol}^{\mathrm{TM}}$ JSM $7000 \mathrm{~F}$ FESEM operating at a voltage of $10 \mathrm{kV}$. Results of the wear tests were evaluated according to the volume of the material loss measured in a Veeco ${ }^{\mathrm{TM}}$ Dektak $6 \mathrm{M}$ Stylus Profiler. Wear test results for each sample are the arithmetic mean of three different measurements.

\section{Results and discussion}

\subsection{Phase identification and thermal analysis}

Figure 2a shows the XRD patterns of the sintered Cu15Ti matrix alloy, Cu15Ti/1 UDD, and Cu15Ti/10 UDD composites. As seen in Fig. 2a, the reflections of $\mathrm{Cu}$ (Bravais lattice: face-centered-cubic (f.c.c.); Space group: Fm3m; $a=0.362 \mathrm{~nm}$; ICDD PDF \# 70-3038) and $\mathrm{Ti}$ (Bravais lattice: Hexagonal, Space group: P63/mmc; $a=0.295 \mathrm{~nm}, c=0.4682 \mathrm{~nm}$; ICDD PDF \# 44-1294) can be observed in the XRD pattern of all the sintered samples. In addition to these phases, peaks belonging to diamond (Structure: A4 Diamond cubic; Space group: Fd3m; $a=0.356 \mathrm{~nm}$; ICDD PDF \# 65-0537) can be identified in the sintered $\mathrm{Cu} 15 \mathrm{Ti} / 1$ UDD and Cu15Ti/10 UDD composites. A small reflection peak belonging to the $\mathrm{CuO}$ phase (Bravais lattice : base centered monoclinic; Space group : $\mathrm{C} 2 / \mathrm{c}$; $a=0.467 \mathrm{~nm}, b=0.343 \mathrm{~nm}, c=0.513 \mathrm{~nm}, \beta=99.42^{\circ}$; ICDD PDF \# 89-5895), as previously reported in the study of Fathima et al. [30] for $\mathrm{Cu}$-oxide nanorods, is also present in the XRD patterns of the sintered CuTi/10 UDD composite. It is evident that the reflections of copper show a remarkable intensity reduction and peak broadening with increasing nanodiamond content indicating crystallite size refinement as well as the accumulation of internal strain in copper. Contrary to the reported XRD results for the $\mathrm{Cu}$-nanodiamond composites [20, 28], no impurities or contaminations originating from the milling media could be detected in the XRD analysis of $\mathrm{Cu} 15 \mathrm{Ti} / 1$ UDD and Cu15Ti/10 UDD sintered samples (Fig. 2a). In addition, no intermetallic phases were detected in the XRD patterns of sintered samples. However, pat-
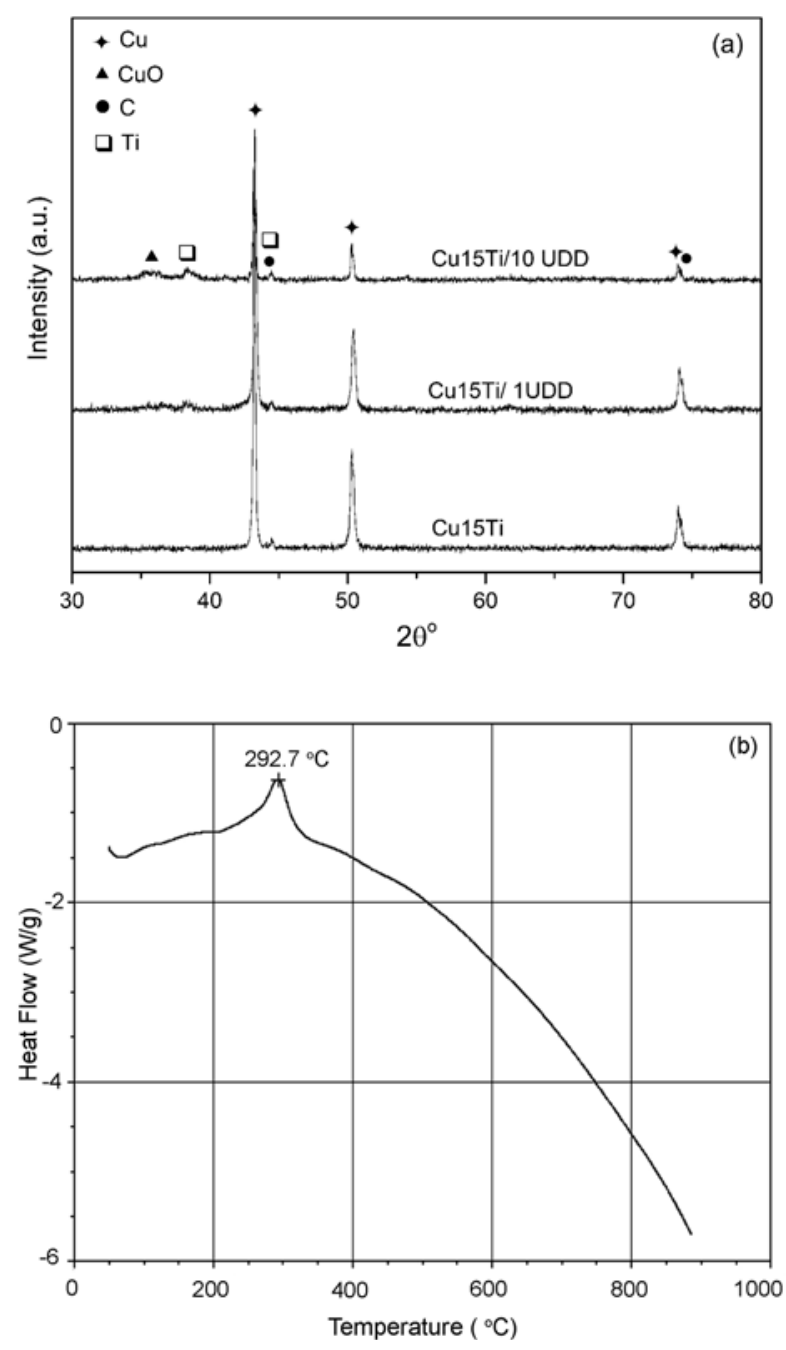

Fig. 2. (a) XRD patterns of the MA'd and sintered Cu15Ti matrix alloy and the $\mathrm{Cu} 15 \mathrm{Ti} / 1 \mathrm{UDD}$ and $\mathrm{Cu} 15 \mathrm{Ti} / 10 \mathrm{UDD}$ samples, (b) DSC curve of the Cu15Ti/10 UDD powders MA'd for $120 \mathrm{~min}$.

terns belonging to $\mathrm{Cu} / \mathrm{Ti}$ reaction products such as $\mathrm{CuTi}, \mathrm{Cu}_{4} \mathrm{Ti}, \mathrm{Cu}_{4} \mathrm{Ti}_{3}$, and $\mathrm{CuTi}_{2}$ were observed in the XRD results of some reported literature [21, 22, $24,31]$. For instance, a weak $\mathrm{Cu}_{3} \mathrm{Ti}$ peak was identified in the XRD analysis by Cheng et al. [31] who prepared $\mathrm{Cu}-15$ wt.\% Ti reinforced with diamond particles. Similarly, Shiue et al. [21] observed the $\mathrm{CuTi}_{2}$, $\mathrm{CuTi}$, and $\mathrm{Cu}_{4} \mathrm{Ti}_{3}$ intermetallics for the brazed $\mathrm{Cu}$ and $\mathrm{Ti}$ with silver-based alloy at $980^{\circ} \mathrm{C}$. In addition, Xian et al. [24] claimed that the differences in the interfacial reaction products mainly depend on the fabrication temperature, time, and the thickness of $\mathrm{Ti}$ layer which diffused into $\mathrm{Cu}$ for coating experiments. Therefore, it is believed that emergence of these intermetallic phases may be due to a higher processing temperature than that was used in the present study $\left(890^{\circ} \mathrm{C}\right)$.

In order to obtain useful information about struc- 

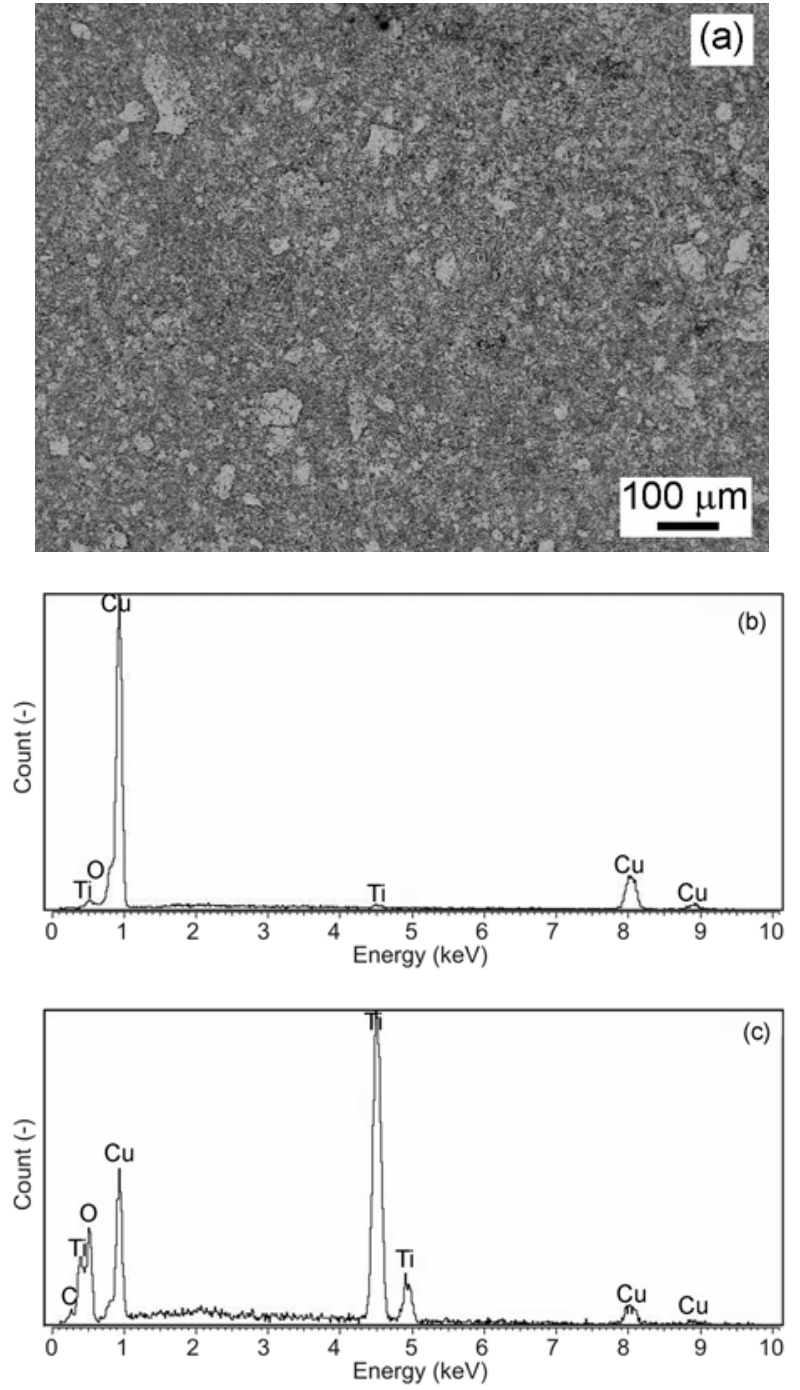

Fig. 3. SEM images of (a) the Cu15Ti matrix alloy and corresponding EDS analyses taken from the (b) bright and (c) dark regions.

tural changes during solid-state sintering, a nonisothermal DSC analysis was performed on the Cu15Ti/10 UDD powders MA'd for $120 \mathrm{~min}$. The DSC curve of the MA'd Cu15Ti/10 UDD powders given in Fig. 2b exhibits only an exothermic peak at $292{ }^{\circ} \mathrm{C}$ belonging to the formation of a copper oxide phase. This confirms the XRD results obtained from sintered samples (Fig. 2a). Moreover, based on the DSC analysis and XRD investigations, the crystal structure of nanodiamond particles was preserved, and nanodiamond particles did not decompose into graphite after sintering at $890^{\circ} \mathrm{C}$. In the present study, the exothermic peak observed in DSC analysis was similar to that recorded for copper oxide nanorods which were synthesized using different surfactant micelles [30]. Because of high oxygen affinity of $\mathrm{Cu}$ powders, high sintering temperatures and controlled atmospheres are
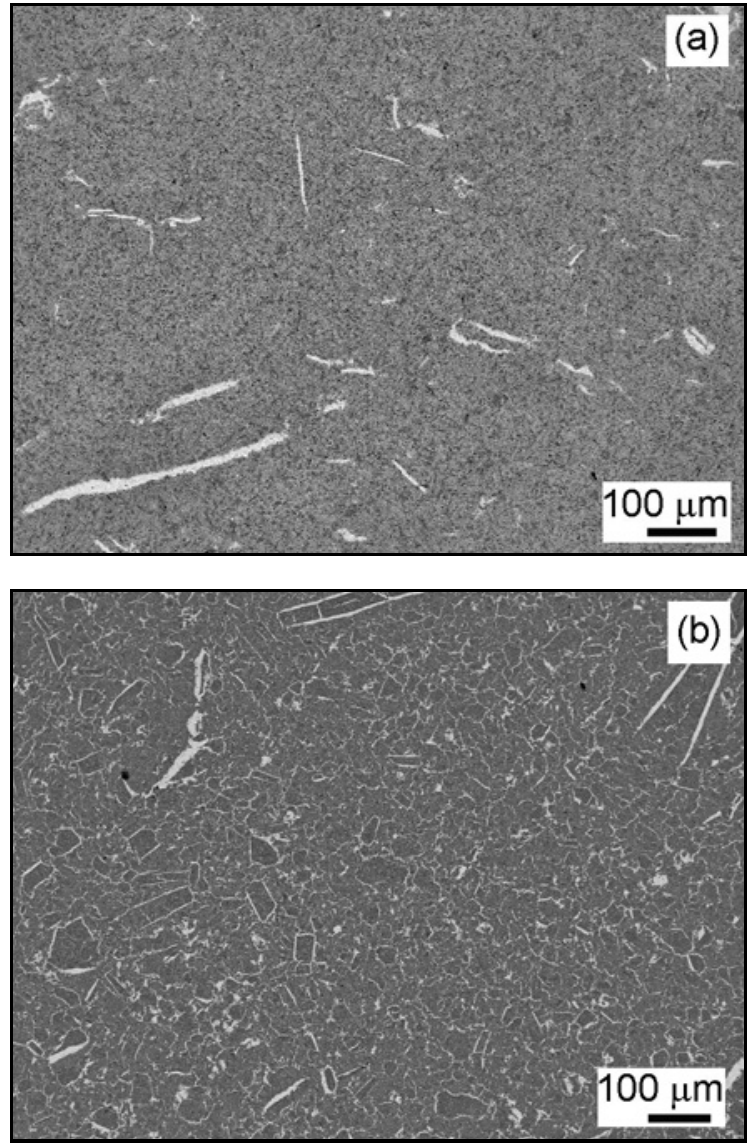

Fig. 4. SEM images of (a) the Cu15Ti matrix alloy and (b) the $\mathrm{Cu} 15 \mathrm{Ti} / 10$ UDD composite.

both necessary to remove oxides from the powder surface. Thus, in the present study before the ball-milling process, the powder mixtures were loaded under Ar atmosphere and were sintered in $\mathrm{H}_{2}$ and $\mathrm{N}_{2}$ atmospheres (Fig. 1) to prevent the formation of any oxide impurities. However, XRD results of the sintered samples indicated the formation of the $\mathrm{CuO}$ phase after sintering process. Therefore, it can be suggested that the natural oxide layers covering the powders are difficult to be reduced during sintering even though required atmosphere with the high sintering temperature exist.

\subsection{SEM investigations}

Figure 3 shows the back-scattered SEM image of the $\mathrm{Cu} 15 \mathrm{Ti}$ alloy and corresponding energy dispersive spectra (EDS) from bright (Fig. 3b) and dark (Fig. 3c) regions. EDS spectra revealed that dark regions are composed of $\mathrm{Ti}$ particles, whereas bright areas belong to the copper phase. These results are consistent with the XRD results in Fig. 2a. As shown in Fig. 3a, uniformly distributed porosities having sizes between 0.3 and $0.5 \mu \mathrm{m}$ can be observed in the microstructure of the Cu15Ti matrix alloy. Figure 4 shows SEM im- 

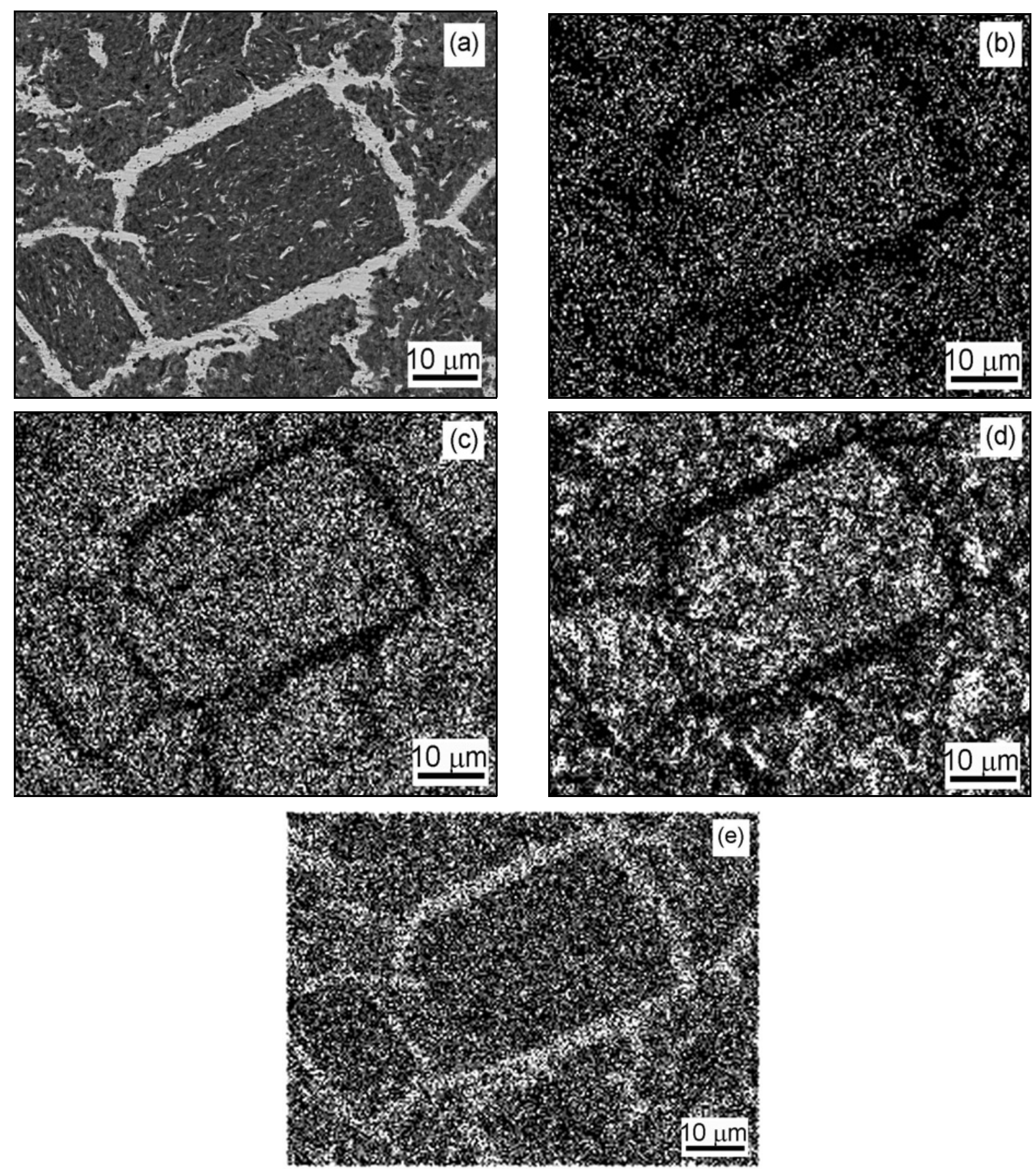

Fig. 5. (a) SEM micrograph of the sintered Cu15Ti/10 UDD composite and corresponding EDS map distributions of (b) $\mathrm{C}$, (c) $\mathrm{O}$, (d) $\mathrm{Ti}$, and (e) $\mathrm{Cu}$.

ages of the sintered $\mathrm{Cu} 15 \mathrm{Ti} / 1 \mathrm{UDD}$ and $\mathrm{Cu} 15 \mathrm{Ti} / 10$ UDD composites. A significant microstructural difference was observed between the $\mathrm{Cu} 15 \mathrm{Ti}$ matrix alloy (Fig. 3a), and the UDD reinforced Cu15Ti/1 UDD (Fig. 4a) and Cu15Ti/10 UDD (Fig. 4b) composites. As seen in the SEM micrograph of the Cu15Ti/1 UDD composite (Fig. 4a), frame-like bright regions are separated from grey regions, and their amounts increase in the $\mathrm{Cu} 15 \mathrm{Ti} / 10$ UDD composite sample with increasing UDD content (Fig. 4b).
In order to identify the present phases and their distributions in the $\mathrm{Cu} 15 \mathrm{Ti} / 10 \mathrm{UDD}$ composite, series of elemental maps were performed for the elements lines of $\mathrm{C} \mathrm{K} \alpha$, $\mathrm{O} \mathrm{K} \alpha$, Ti $\mathrm{K} \alpha, \mathrm{Cu} \mathrm{K} \alpha$ (Fig. 5). Figure 5 a gives the detailed frame-like $\mathrm{Cu}$-rich structures for the $\mathrm{Cu} 15 \mathrm{Ti} / 10$ UDD composite sample. SEM image for the sintered $\mathrm{Cu} 15 \mathrm{Ti} / 10 \mathrm{UDD}$ composite and corresponding EDS maps of the $\mathrm{C}, \mathrm{O}, \mathrm{Ti}$, and $\mathrm{Cu}$ elements are given in Figs. 5b-e. Elemental EDS mappings of Ti and $\mathrm{C}$ in Fig. 5 indicate that the UDD particles and $\mathrm{Ti}$ 

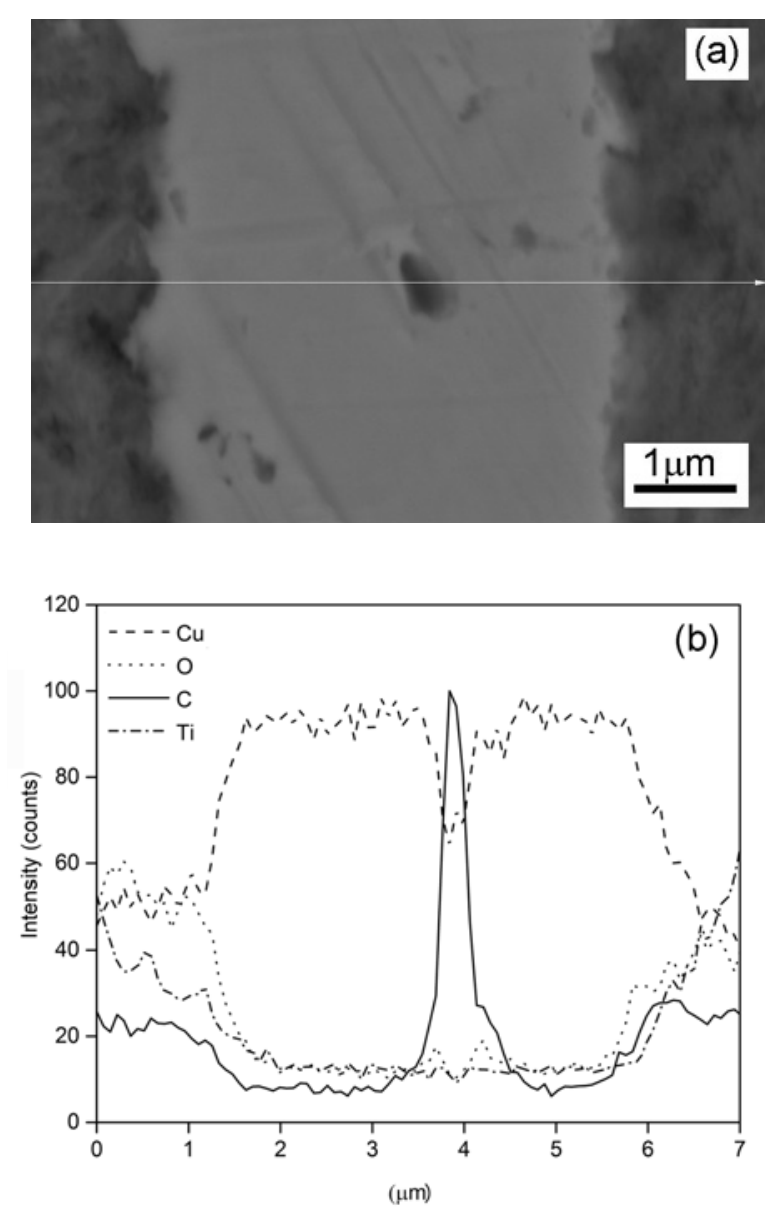

Fig. 6a,b. EDS line scan analysis across the interface between the matrix and $\mathrm{Cu}$-rich zone of the $\mathrm{Cu} 15 \mathrm{Ti} / 10 \mathrm{UDD}$ composite.

particles are uniformly distributed in the $\mathrm{Cu} 15 \mathrm{Ti} / 10$ UDD sample. From Figs. 5c,e inter-lapping of $\mathrm{O}$ and $\mathrm{Cu}$ elements is noticeable on almost the entire surface of the sample except in the frame-like regions. As shown in Fig. 5e, $\mathrm{Cu}$ occupies the frame-like regions, and thus it can be suggested that these framelike regions belong to the free $\mathrm{Cu}$ layer. Similar copper layers surrounding nanocrystalline regions of $\mathrm{Cu}$ and $\mathrm{Al}_{2} \mathrm{O}_{3}$ were reported by Hwang et al. [32] who studied the mechanochemical synthesis of nanocrystalline $\mathrm{Al}_{2} \mathrm{O}_{3}$ dispersed $\mathrm{Cu}$ composites. They suggested that these free copper layers were formed due to some unreacted copper powders after sintering [32]. Based on the EDS map analysis shown in Fig. 5b, well-distributed bright spots are assigned to UDD agglomerates.

In order to examine the changes in element distribution in the frame-like structure, the EDS linescanning across the interface between the matrix and the $\mathrm{Cu}$-rich zone of the $\mathrm{Cu} 15 \mathrm{Ti} / 10 \mathrm{UDD}$ composite sample was carried out for copper, diamond, titanium, and oxygen, and this is given in Fig. 6. As in Fig. 6, the oxygen signal prominently exists at the interface
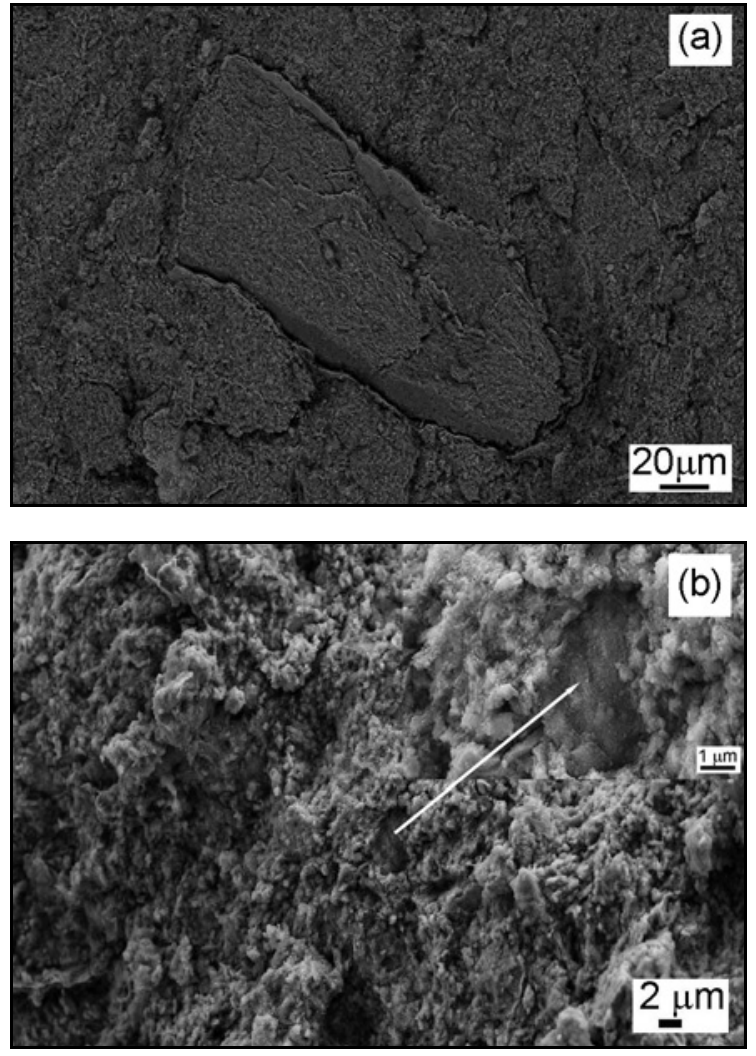

Fig. 7. (a) Transverse and (b) longitudinal section of the Cu15Ti/10 UDD composite sample. A high-resolution SEM image is showing the UDD particles in (b) as an inset.

between UDD particles and $\mathrm{Cu}$-rich zone. The reaction layers which provide the strong bonding between diamond and matrix interface were not produced at the interface. These four profiles in Figure $6 \mathrm{~b}$ show an inner layer rich in $\mathrm{Cu}$ and a Ti-free layer. In addition, an increase in $\mathrm{Ti}$ concentration in the matrix of $\mathrm{Cu} 15 \mathrm{Ti} / 10$ UDD composite sample was observed from the line-scan profile. The concentration profiles of $\mathrm{Ti}, \mathrm{C}$, and $\mathrm{O}$ increase near the interface between $\mathrm{Cu}$ -rich zone and the matrix exhibiting no obvious overlap between $\mathrm{Cu}$ and $\mathrm{O}$ signals in $\mathrm{Cu}$-rich zone, and this compliments the EDS-map analysis given in Fig. 5c. Further, Fig. 6 reveals that UDD particles having an average size between $200-350 \mathrm{~nm}$ are dispersed within the frame-like $\mathrm{Cu}$-rich region. In other words, it is likely that the starting agglomerates of UDD particles did not completely disintegrate into primary particles which have a particle size of $2-50 \mathrm{~nm}$ [13]. From the line-scan analysis (Fig. 6b), the thickness of $\mathrm{Cu}$-rich zone can be determined as approximately $5 \mu \mathrm{m}$.

The fracture surfaces of the Cu15Ti/10 UDD composite broken in longitudinal and transverse direction (press) were investigated. Figure 7a shows a transverse section of $\mathrm{Cu} 15 \mathrm{Ti} / 10$ UDD sample where the unreacted frame-like $\mathrm{Cu}$-rich structure exists. These struc- 
Ta ble 1. Microhardness, density, and relative wear resistance values of the MA'd and sintered Cu15Ti matrix alloy and $\mathrm{Cu} 15 \mathrm{Ti} / 1 \mathrm{UDD}$ and $\mathrm{Cu} 15 \mathrm{Ti} / 10 \mathrm{UDD}$ composites

\begin{tabular}{lccccc}
\hline Samples & $\begin{array}{c}\rho_{\text {measured }}{ }^{*} \\
\left(\mathrm{~g} \mathrm{~cm}^{-3}\right)\end{array}$ & $\begin{array}{c}\rho_{\text {theoretical }}{ }^{* *} \\
\left(\mathrm{~g} \mathrm{~cm}^{-3}\right)\end{array}$ & $\begin{array}{c}\text { Relative density } \\
(\%)\end{array}$ & $\begin{array}{c}\text { Hardness } \\
(\mathrm{GPa})\end{array}$ & $\begin{array}{c}\text { Relative wear } \\
\text { resistance }\end{array}$ \\
\hline $\mathrm{Cu} 15 \mathrm{Ti}$ & $5.71 \pm 0.39$ & 7.75 & 73.6 & $1.16 \pm 0.07$ & 1 \\
$\mathrm{Cu} 15 \mathrm{Ti}$ /1 UDD & $5.23 \pm 0.32$ & 6.60 & 79.2 & $1.51 \pm 0.09$ & 10.43 \\
$\mathrm{Cu} 15 \mathrm{Ti} / 10 \mathrm{UDD}$ & $4.42 \pm 0.46$ & 5.97 & 74.0 & $1.88 \pm 0.11$ & 2.03 \\
\hline
\end{tabular}

*Density values were measured by Archimedes' method.

**Theoretical density values were calculated based on the rule of mixture.

tures are isolated from the matrix material, and some cracks appear near the interfaces. This is likely due to the high oxygen concentrations, detected by linescan analysis (Fig. 6), which are present near the interfaces. Figure $7 \mathrm{~b}$ shows a SEM micrograph pertaining to the longitudinal section of the Cu15Ti/10 UDD sample and a high-resolution inset SEM image showing the UDD particles, revealing ductile fracturing in Cu15Ti/10 UDD sample. In addition, a different fracture surface morphology can be observed in the longitudinal section of the Cu15Ti/10 UDD composite in contrast to the transverse one (Fig. 7a). The formation of $\mathrm{CuO}$ at the interfaces between $\mathrm{Cu}$ matrix and UDD reinforcement particles prevents strong bonding, and $\mathrm{Ti}$ addition does not inhibit bulk copper layer formation. A similar result was also reported by Zhang et al. [33] who studied Al-Cu matrix composites reinforced with SiC. They also interpreted that undissolved copper-rich second phase was located mainly at the particle surfaces having a negative effect on the strength of the composite.

\subsection{Hardness and wear results}

Microhardness values of the Cu15Ti matrix alloy and $\mathrm{Cu} 15 \mathrm{Ti} / 1 \mathrm{UDD}$ and $\mathrm{Cu} 15 \mathrm{Ti} / 10$ UDD composite samples are given in Table 1 . It is clearly evident from Table 1 that the hardness of Cu15Ti matrix alloy increases substantially with increasing UDD content. Based on this observation, it can be stated that the average hardness values increase with the amount of nanosized reinforcement particles which impart constraint to localized matrix deformation during indentation. As expected, the highest microhardness value of $1.88 \mathrm{GPa}$ was measured for the sintered Cu15Ti/10 UDD composite containing 10 wt.\% nanodiamond particles. The unreinforced Cu15Ti matrix alloy has a hardness value of $1.16 \mathrm{GPa}$, which is very close to that of the same alloy produced by conventional microwave sintering at $950^{\circ} \mathrm{C}$ under $\mathrm{N}_{2}$ atmosphere [31]. Small standard deviations in the hardness values of the sintered $\mathrm{Cu} 15 \mathrm{Ti} / 1 \mathrm{UDD}$ and $\mathrm{Cu} 15 \mathrm{Ti} / 10$ UDD composites indicate that UDD particles are homogeneously distributed in the Cu15Ti matrix.

Table 1 also gives the relative, measured, and theoretical density values of Cu15Ti matrix alloy, Cu15Ti/1 UDD, and Cu15Ti/10 UDD composite samples as a function of UDD content. The theoretical density values for each sample were calculated using a rule of mixture. Note that density values of $\mathrm{Cu}, \mathrm{Ti}$, and UDD particles are $8.9,4.5$, and $2.7 \mathrm{~g} \mathrm{~cm}^{-3}$ [31], respectively. It is obvious from Table 1 that the density values of sintered samples reduced proportionally by increasing the weight percentage of UDD particles. As stated before, a number of oxide particles are changing with the weight percentage of UDD particles based on SEM/EDS analysis. Therefore, it can be suggested that the low measured densities of the Cu15Ti/1 UDD and Cu15Ti/10 UDD composites correlate well with the amount of UDD together with oxide particles. Clearly, the relative density values improved to 79.2 with the addition of UDD particles of 1 wt.\% into Cu15Ti alloy, whereas the relative density values reduced to 74.0 for the further increment of UDD content $(10 \mathrm{wt} . \%)$ in Cu15Ti alloy. This is because a large amount of oxide particles between the composite powders prevent the composite powders from sintering and this leads to low densification. Although samples were sintered under $\mathrm{H}_{2}$ gas atmosphere for reducing the oxygen, the presence of oxide particles induced low particle-particle contact and this made sintering more difficult. Therefore, the lower densification and higher porosity level were obtained for $\mathrm{Cu} 15 \mathrm{Ti} / 10$ UDD composite compared to $\mathrm{Cu} 15 \mathrm{Ti}$ alloy. Cheng et al. [31] investigated the microstructural evolution of microwave sintering $\mathrm{Cu} / \mathrm{Ti}$ composites reinforced with various diamond contents (1050 vol.\%). They found that relative density of the composites increased up to $25 \mathrm{vol} . \%$ of diamond content and then decreased the value of $75 \%$ for the diamond content of $50 \mathrm{vol} . \%$ drastically, which is close to the relative density values of $\mathrm{Cu} 15 \mathrm{Ti} / 10$ UDD composite in the present study. Poor mechanical properties and high porosity values with the addition of diamond nanoparticles (>2 at.\%) into the matrix resulting in inhomogeneous microstructure were also reported $[17$, 20]. The mechanical properties such as hardness and proof stress were improved in hot extruded samples containing even 20 at.\% of nanodiamond particles in $\mathrm{Cu}$ matrix [19]. 
In the present study, the relative wear resistance of the composite samples was normalized by dividing the wear track area of the sintered composites by that of the unreinforced Cu15Ti matrix alloy. In other words, the wear resistance value of the unreinforced $\mathrm{Cu} 15 \mathrm{Ti}$ matrix alloy was taken as 1 . Wear track areas and the wear volume of the sintered materials were determined by using the depth $(D)$ and width $(W)$ values of wear scars measured by a profilometer. Arithmetic means of three different measurements for each sample were obtained. The measured width and depth of wear scar values are used to compute the volume by means of the following equation [6]:

$$
V=\frac{\pi}{4} W \times D
$$

where $V$ is the wear volume, $W$ is the width, and $D$ is the depth of the wear scar.

It is generally known that the wear resistance of composites containing hard reinforcement particles enhances due to the following reasons [34-36]: (a) improved hardness of the composites, (b) good interfacial bonding between matrix and reinforcement, and (c) homogeneously distributed and well bonded hard reinforcement particles which lead to a great reduction of direct load contact between the composite surface and counterface because of load bearing ability of reinforcement particles. Therefore, considering all these attributes, it is expected that the wear resistance of the sintered Cu15Ti/UDD composites increases with increasing UDD contents. However, quite contrary to the expected, the relative wear resistance of the sintered $\mathrm{Cu} 15 \mathrm{Ti} / 1 \mathrm{UDD}$ composite sample is about 5 times higher than that of the sintered Cu15Ti/10 UDD composite sample, as seen in Table 1. Also evident from Table 1 is that the relative wear resistances of the sintered Cu15Ti/1 UDD and Cu15Ti/10 UDD composites are higher by about ten and two times than that of the Cu15Ti matrix alloy, respectively. A low relative wear resistance of the $\mathrm{Cu} 15 \mathrm{Ti} / 10 \mathrm{UDD}$ composite sample is believed to arise from poor sintering due to the weak bonding between the matrix and the UDD particles associated with a large amount of oxygen. Similarly, Zhang and Alpas [37] reported that the detachment of the reinforcement particles from the worn surfaces shifted the wear resistance of the composites towards to that of the matrix material.

SEM investigations were carried out on the worn surfaces of the sintered Cu15Ti matrix alloy, the Cu15Ti/1 UDD, and Cu15Ti/10 UDD composites. Figure 8a is a general SEM micrograph of the worn surface of the Cu15Ti matrix alloy while Fig. 8b shows a high magnification SEM image of the Cu15Ti matrix alloy revealing surface damage due to wear. Substantial amounts of the dimples and local adherent scars were observed on the worn surface of the Cu15Ti matrix alloy (Fig. 8) associated with deep grooves parallel
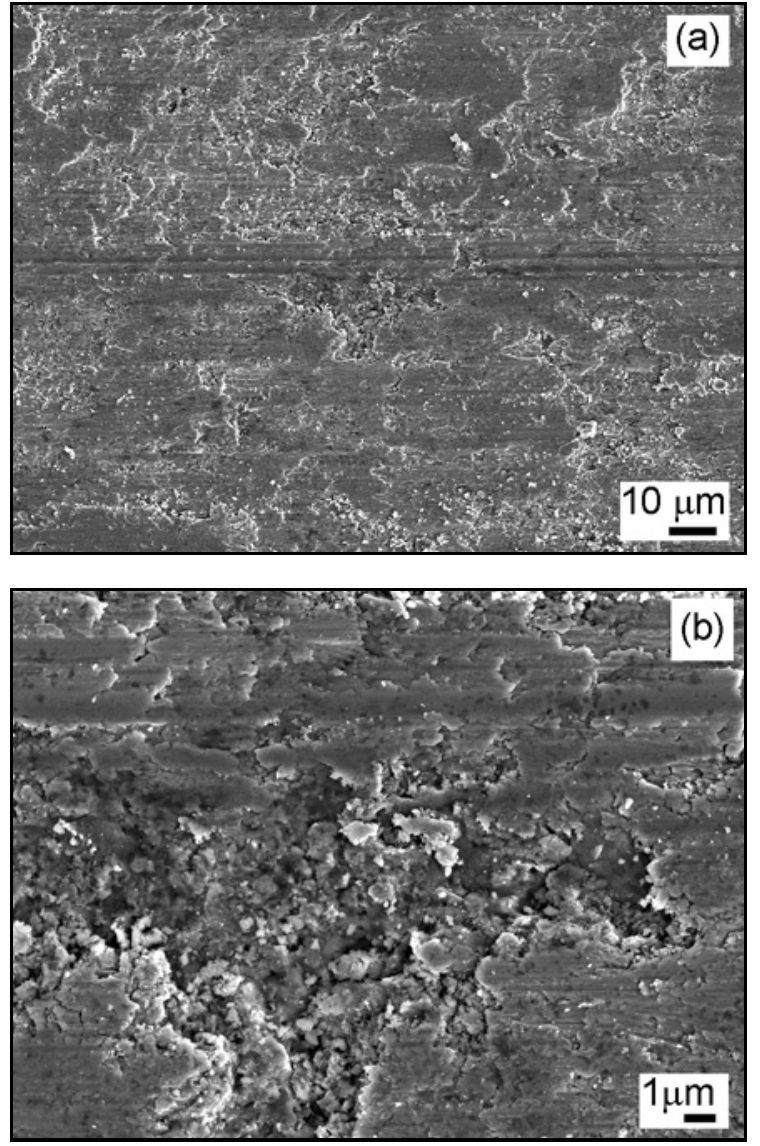

Fig. 8. SEM worn surface appearances of the Cu15Ti matrix alloy taken at (a) low magnification, (b) high magnification.

to the sliding direction. This indicates that abrasive and adhesive wear are likely the dominant wear mechanisms of the Cu15Ti matrix alloy. Further observation of Fig. 8 suggests that there is no evidence of a transferred iron-rich layer from the steel counterface during sliding wear experiments. SEM images of the typical appearances of the worn surfaces of the sintered $\mathrm{Cu} 15 \mathrm{Ti} / 1$ UDD and $\mathrm{Cu} 15 \mathrm{Ti} / 10$ UDD composite samples at high and low magnifications are given in Figs. 9a,b and Figs. 9c,d, respectively. The grooves in the worn surfaces of the sintered Cu15Ti/1 UDD composite (Figs. 9a,b) are much shallower and narrower than those observed in the sintered Cu15Ti matrix alloy shown in Fig. 8. In addition, adhesive wear characteristics were identified and trace tribo-oxide layers which form due to oxide particles scattered on the worn surface can be identified in the Cu15Ti/1 UDD composite (Fig. 9b). Figures 9c,d are the SEM micrographs showing typical oxidative wear appearances taken from the worn surfaces of the Cu15Ti/10 UDD composite at low and high magnifications, respectively. The wear resistance of the sintered Cu15Ti/10 UDD composite decreased with increased amount of 

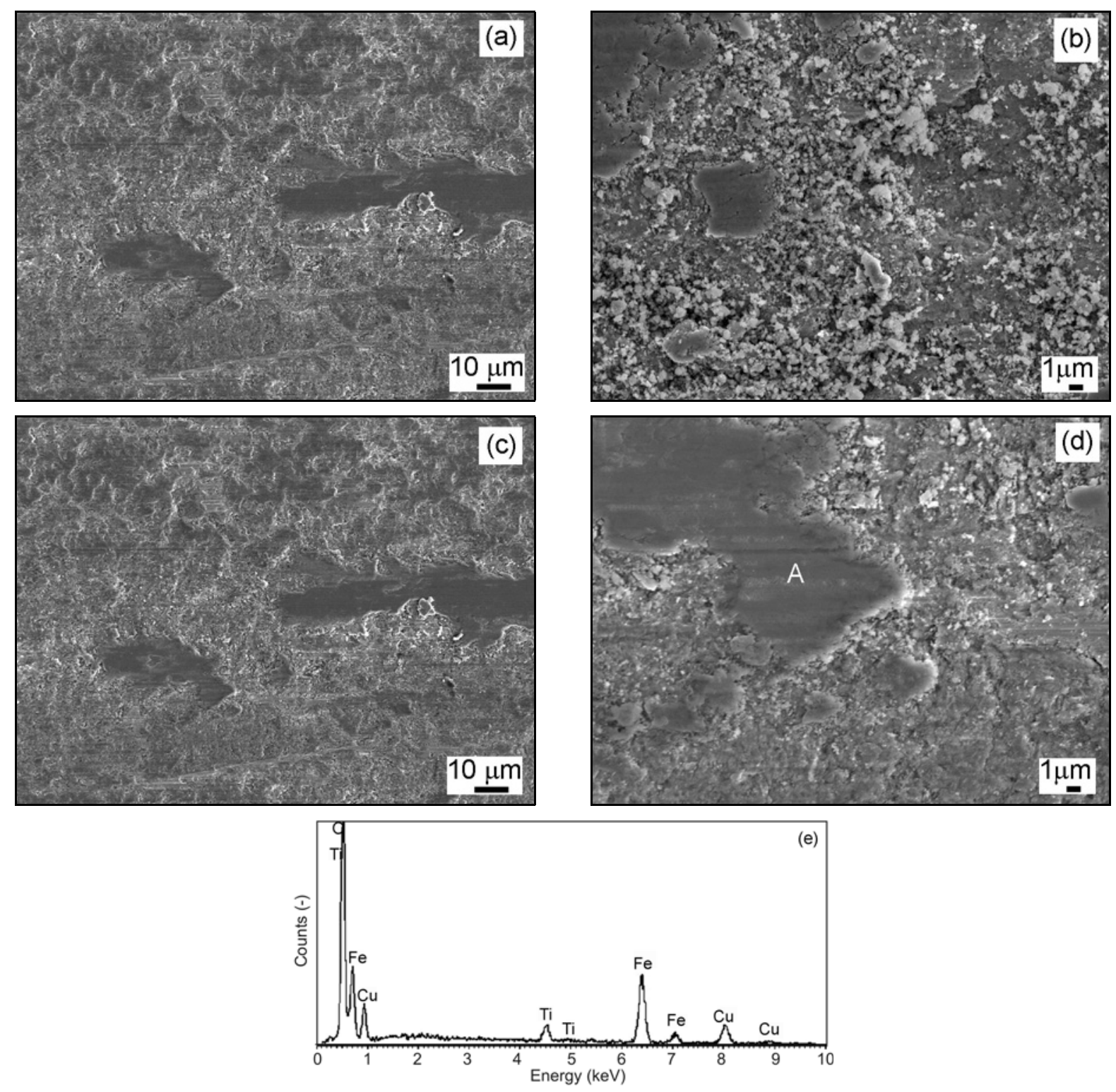

Fig. 9. SEM micrographs from the inner regions of wear tracks of the MA'd and sintered Cu15Ti/1 UDD composite taken at: (a) low and (b) high magnification, and those of the Cu15Ti/10 UDD composite taken at: (c) low magnification, (d) high magnification, and (e) corresponding EDS analysis taken from region A.

the oxide phase, even when its hardness increased (Table 1). It is believed that the oxide particles in the $\mathrm{Cu} 15 \mathrm{Ti} / 10$ UDD composite prevented particleparticle contacts and the UDD particles were removed easily from the worn surface of the sintered $\mathrm{Cu} 15 \mathrm{Ti} / 10$ UDD. In order words, a high amount of oxide particles in the microstructure of the sintered Cu15Ti/10 UDD composite sample contributed to lower wear resistance than that of the sintered $\mathrm{Cu} 15 \mathrm{Ti} / 1$ UDD. The presence of the oxide particles is also verified by the XRD patterns of the sintered composite samples shown in Fig. 2a, where $\mathrm{CuO}$ peaks exist in both the sintered $\mathrm{Cu} 15 \mathrm{Ti} / 1 \mathrm{UDD}$ and $\mathrm{Cu} 15 \mathrm{Ti} / 10$ UDD composites. This suggests that oxidative wear appears to be the main wear mechanism for the $\mathrm{Cu} 15 \mathrm{Ti} / 1 \mathrm{UDD}$ and
Cu15Ti/10 UDD composites. A high amount of oxide particles scattered on worn surfaces of the Cu15Ti/10 UDD composite. This may be due to delamination of the thin tribo-oxide layer as well as pulling out of UDD particles which lead to the presence of a substantial amount of oxide particles. As seen in Fig. 9d and corresponding EDS spectra (Fig. 9e) taken from a layer (indicated as A), it can be suggested that this layer comprising oxides of Fe particles was detached from the steel counterface due to the abrasive action of the UDD particles. The high oxygen concentration in the EDS analysis indicates that iron particles might be oxidized during their transfer to the surface of the sintered Cu15Ti/10 UDD composite sample.

Cheng et al. [31] reported that wear volume de- 
creased very rapidly with the addition of various amounts of diamond particles $(10,20$, and 25 vol.\%) and it increased for the $\mathrm{Cu} / 15 \mathrm{wt} . \%$ Ti composite containing 30-50 vol.\% diamond particles due to debonding between diamond and the $\mathrm{Cu} / \mathrm{Ti}$ matrix material. However, in the present study, a rather low wear resistance value was obtained with the addition of 10 wt.\% of UDD particles to the Cu15Ti matrix alloy, lower than the diamond content used in Cheng et al.'s work [31]. Therefore, the lower wear resistance in Cu15Ti/10 UDD sample is probably due to the high specific surface area of the UDD particles $\left(\sim 277 \mathrm{~m}^{2} \mathrm{~g}^{-1}\right)$ [13] which leads to high particlematrix interfaces clearly observed from the line-scan EDS analysis (Fig. 6). Increasing the number of interfaces increases the defect areas which contribute to low wear resistance when low densification is obtained between the matrix and reinforcement [20].

\section{Conclusions}

In the present study, $\mathrm{Cu}-15$ wt.\% Ti matrix alloy and its composites reinforced with 1 and $10 \mathrm{wt} . \%$ UDD were produced using mechanical alloying and sintering. Based on the experimental results reported in this study, the following conclusions can be drawn:

1. XRD investigations revealed the presence of the $\mathrm{Cu}, \mathrm{Ti}$, and diamond phases in the $\mathrm{Cu} 15 \mathrm{Ti} / 1 \mathrm{UDD}$ and $\mathrm{Cu} 15 \mathrm{Ti} / 10 \mathrm{UDD}$ composite samples. In addition to these phases, $\mathrm{CuO}$ phase is present in all sintered samples. Increasing UDD content improves the hardness of the sintered composites. A maximum hardness value of $1.88 \mathrm{GPa}$ was measured for the $\mathrm{Cu} 15 \mathrm{Ti} / 10$ UDD composite which is about 1.6 times higher than that of the Cu15Ti matrix alloy.

2. The line-scan and fracture surface analysis results of the $\mathrm{Cu} 15 \mathrm{Ti} / 10 \mathrm{UDD}$ composite sample reveal that weak bonding between the diamond nanoparticles and the matrix exists probably due to the high concentration of oxygen at the particle-matrix interface.

3. Contrary to the Cu15Ti/1 UDD composite, the Cu15Ti/10 UDD composite exhibited a relatively low wear resistance due to weak bonds between matrix and UDD particles associated with oxide particles.

4. The worn surface of the $\mathrm{Cu} 15 \mathrm{Ti} / 10$ UDD composite was completely different from that of the unreinforced Cu15Ti matrix alloy and was covered with oxide particles. EDS spectra taken from the Cu15Ti/10 UDD composite indicated that the worn surface consisted mainly of $\mathrm{Fe}$ and $\mathrm{O}$ elements detached from the counterface steel ball. This indicates that the mild oxidative wear mechanism operates during the wear test, i.e. wear proceeds mainly by the formation of an oxidative layer in the worn surface and its spalling.

\section{Acknowledgement}

The authors would like to acknowledge the State Planning Organization (DPT) of Turkey for funding the project entitled "Development of Al-Cu Based Metal Matrix Composites via Powder Metallurgy Techniques" with the project number 90189 .

\section{References}

[1] Chi, F., Schmerling, M., Eliezer, Z., Marcus, H. L., Fine, M. E.: Mater. Sci. Eng. A, 190, 1995, p. 181. doi:10.1016/0921-5093(95)09617-5

[2] Ying, D. Y., Zhang, D. L.: Mater. Sci. Eng. A, 286, 2000, p. 152. doi:10.1016/S0921-5093(00)00627-4

[3] Naser, J., Riehemann, W., Ferkel, H.: Mater. Sci. Eng. A, 234, 1997, p. 467. doi:10.1016/S0921-5093(97)00269-4

[4] Carvalho, P. A., Fonseca, I., Marques, M. T., Correia, J. B., Almeida, A., Vilar, R.: Acta Mater., 53, 2005, p. 967. doi:10.1016/i.actamat.2004.10.042

[5] Marques, M. T., Livramento, V., Correia, J. B., Almeida, A., Vilar, R.: Mater. Sci. Eng. A, 399, 2005, p. 382. doi:10.1016/i.msea.2005.03.090

[6] Brendel, A., Popescu, C., Schurmann, H., Bolt, H.: Surf. Coat. Tech., 200, 2005, p. 161. doi:10.1016/j.surfcoat.2005.02.018

[7] Yoshida, K., Morigami, H.: Microelect. Rel., 44, 2004, p. 303. doi:10.1016/S0026-2714(03)00215-4

[8] Weber, L., Tavangar, R.: Scripta Mater., 57, 2007, p. 988. doi:10.1016/i.scriptamat.2007.08.007

[9] Hamid, Z. A., Moustafa, S. F., Morsy, F. A., Khalifa, N. A. A., Mouez, F. A.: Natur. Sci., 11, 2011, p. 936. doi:10.4236/ns.2011.311120

[10] Pecheva, E., Pramatarova, L., Fingarova, D., Hikov, T., Dineva, I., Karagyozova,Z., Stavrev, S.: J. Optoelectron. Adv. Mat., 11, 2009, p. 1323.

[11] Wilson, J., Kulisch, W.: Diamond Thin Films. Berlin, Academic Verlag 1996.

[12] Goudouri, O. Z., Chatzistavrou, X., Kantiranis, N., Zorba, T., Koidis, P., Paraskevopoulos, K.: Proceedings of the XXII Pan-Hellenic Conference of Solid Natural Situation and Science of Materials. Patras, University of Patras 2006, p. 24.

[13] Kaftelen, H., Ovecoglu, M. L.: J. Compos. Mater., 46, 2012, p. 1521. doi:10.1177/0021998311421636

[14] Hanada, K., Sano, T.: J. Nanosci. Nanotech., 10, 2010, p. 2735. doi:10.1166/jnn.2010.1378

[15] Burkat, G. K., Fujimura, T., Dolmatov, V. Y., Orlova, E. A., Veretennikova, M. V.: Diam. Rel. Mater., 14, 2005, p. 1761. doi:10.1016/j.diamond.2005.08.004

[16] Kulakova, I. I.: Physics of the Solid State, 46, 2004, p. 636. doi:10.1134/1.1711440

[17] Hanada, K., Mayuzumi, M., Nakayama, N., Sano, T.: J. Mater. Proc. Techn., 119, 2001, p. 216. doi:10.1016/S0924-0136(01)00946-3

[18] Hsieh, Y. Z., Chen, J. F., Lin, S. T.: J. Mater. Sci., 35, 2000, p. 5383. doi:10.1023/A:1004855130887

[19] Hanada, K., Yamamoto, K., Taguchi, T., Osawa, E., Inakuma, M., Livramento, V., Correia, J. B., Shohoji, N.: Diam. Relat. Mater., 16, 2007, p. 2054. doi:10.1016/j.diamond.2007.07.008 
[20] Hanada, K., Nakayama, K., Sano, T., Imahori, A., Negishi, H., Mayuzumi, M.: Mater. Manufact. Proc., 15, 2000, p. 325 . doi: $10.1080 / 10426910008912991$

[21] Shiue, R. K., Wu, S. K., Chan, C. H.: J. Alloy Compd., 372, 2004, p. 148. doi:10.1016/j.jallcom.2003.09.155

[22] Kundu, S., Ghosh, A., Laik, A., Bhanumurthy, K., Kale, G. B., Chatterjee, S.: Mater. Sci. Eng. A, 407, 2005, p. 154. doi:10.1016/j.msea.2005.07.010

[23] Noma, T., Sawaoka, A.: J. Am. Ceram. Soc., 68, 1985, p. C271. doi:10.1111/j.1151-2916.1985.tb11528.x

[24] Xian, L., Yang, Y. Q., Mei, Y. W., Bin, H., Meini, Y. N., Yan, C.: Scripta Mater., 56, 2007, p. 569. doi:10.1016/j.scriptama.2006.12.041

[25] Schubert, T., Trindade, B., Weissgaerber, T., Kieback, B.: Mater. Sci. Eng. A, 475, 2008, p. 39. doi:10.1016/i.msea.2006.12.146

[26] Dewar, B., Nicholas, M., Scott, P. M.: J. Mater. Sci., 11, 1976, p. 1083. doi:10.1007/BF00553116

[27] Livramento, V., Correia, J. B., Shohoji, N., Osawa, E.: Diam. Relat. Mater., 16, 2007, p. 202. doi:10.1016/i.diamond.2006.05.008

[28] Nunes, D., Livramento, V., Mateus, R., Correia, J. B., Alves, L. C., Vilarigues, M., Carvalho, P. A.: Mater. Sci. Eng. A, 528, 2011, p. 8610. doi:10.1016/j.msea.2011.08.048

[29] Caron, R. N., Barth, R. G., Tyler, D. E.: ASM Handbook. Metallography and Microstructures of Copper and its Alloys. 9th Volume. Materials Park, ASM International 2004.
[30] Fathima, N. N., Rajaram, A., Sreedhar, B., Mandal, A. S.: Indian J. Sci. Tech., 1, 2008, p. 1. doi:10.17485/ijst\%2F2008\%2Fv1i7\%2F 29592

[31] Cheng, Y. H., Wu, Y. P., Zhu, W. X., Chen, J. G., Qiao, X. L., Fan, Y., Pan, X. X.: J. Mater. Sci. Lett., 18, 1999, p. 1933. doi:10.1023/A:1006641400866

[32] Hwang, S. J., Wexler, D., Calka, A.: J. Mater. Sci., 39, 2004 , p. 4659. doi:10.1023/B:JMSC.0000034165.79830.d7

[33] Zhang, R., Gao, L., Guo, J. K.: Composites Part A Appl. Sci. Manufact., 35, 2004, p. 1301. doi:10.1016/j.compositesa.2004.03.021

[34] Ramesh, C. S., Ahmed, R. N., Mujeebu, M. A., Abdullah, M. Z.: Mater. Design, 30, 2009, p. 1957. doi:10.1016/j.matdes.2008.09.005

[35] Mahmoud, E. R. I., Takahashi, M., Shibayanagi, T., Ikeuchi, K.: Wear, 268, 2010, p. 1111. doi:10.1016/i.wear.2010.01.005

[36] Bobrovnitchii, G. S., Diegues Skury, A. L., Monteiro, S. N., Tardim, R. C.: In: Proceedings of Advanced Powder Technology VII. Eds.: Salgado, L., Ambrozio, F. Zurich, Trans Tech Publications Ltd. 2010, p. 848.

[37] Alpas, A. T., Zhang, J.: Metal. Mater. Trans. A, 25, 1994, p. 969. doi: $10.1007 / \mathrm{BF} 02652272$ 